\title{
Energy taxes in three political economy models ${ }^{1}$
}

\author{
Helmuth Cremer \\ Toulouse School of Economics \\ (IDEI and GREMAQ) \\ Philippe De Donder \\ Toulouse School of Economics \\ (IDEI and GREMAQ-CNRS) \\ Firouz Gahvari \\ Department of Economics \\ University of Illinois at Urbana-Champaign
}

December 2006

Revised, June 2007

${ }^{1}$ We thank two anonymous referees and the Editor, Don Fullerton, for their useful comments and advice. 


\begin{abstract}
This paper presents two alternatives to the traditional majority-voting equilibrium approach in an attempt to account for the existence of environmental taxes - as opposed to subsidies - given that such taxes are regressive and that the income distribution is skewed to the right. These are the probabilistic-voting model and Roemer's (2001) model of political competition with the "Party Unanimity Nash Equilibrium" (PUNE) as the equilibrium solution concept. The economic model is calibrated on the basis of the US data. The paper shows that while the majority-voting approach calls for a massive subsidy, the PUNE approach leads to huge environmental taxes. Our tentative results suggest that the probabilistic model, wherein parties assume that the proportion of unbiased voters is the same in all categories of income, explains the observed US energy taxes the best. Alternatively, we can not reject the hypothesis that policymakers follow a utilitarian objective.
\end{abstract}

Key words: Emission taxes, political competition, majority-equilibrium, PUNE.

JEL Classification: H23, D72. 


\section{Introduction}

Energy taxes are often considered to be regressive. Poterba (1991) has estimated that, with very few exceptions, expenditure shares decline with income for polluting goods such as gasoline, fuel oil, natural gas, and electricity. In light of this, and given the almost universally observed right-skewed income distributions around the world, it is difficult to find a positive explanation for the existence of such taxes. ${ }^{1}$ The traditional majority-voting equilibrium approach would call for a subsidy on these goods and not a tax: Unless deterred by an excessive efficiency cost, the median voter would advocate a subsidy to energy consumption as a means for income redistribution. Even more puzzling is that the costs of taxation affect only the voting citizens, whereas the benefits that are environmental in nature are often shared globally (in terms of reducing emissions). The associated free-rider problem makes the case for taxation even weaker.

This puzzle points to a natural question: Are there political economy models that can explain the existence of positive energy taxes in the US? To this end, we examine the predictions of three competing models for the determination of environmental taxes. These are the majority-voting model, the probabilistic-voting model, and Roemer's (2001) model of political competition, with the "Party Unanimity Nash Equilibrium" (PUNE) as the equilibrium solution concept. We then contrast the predictions of these models with an estimate of the energy taxes in the US.

The first model is the simple and most commonly-used majority-voting model of Downs (1951). Within this setup, we study the cases where all citizens vote, and where citizens differ in their probability of voting, so that the median voter (as opposed to the "median citizen") is decisive. The second model is the probabilistic voting approach; see Persson and Tabellini (2000). This framework posits that parties are purely office-motivated; citizens, on the other hand, care not only for policies but also for the political parties that propose the policies. That is, they may strictly prefer one party to another, even if the parties propose identical policies. Preferences for a particular party, or what is

\footnotetext{
${ }^{1}$ Admittedly, voters may vote for a package of tax and expenditure policies wherein the redistributive effects of energy taxes are offset through the expenditure side of the package. In practice, however, one seldom observes voting over comprehensive tax design issues. Instead, it is often piecemeal tax reform proposals that are put to vote. Voters are then concerned only with the redistributive ramifications of the particular tax policy proposed. See also Cremer et al. (2004b, 2007) who, while not considering a comprehensive package, study a two-dimensional policy in which revenues from energy taxes are earmarked for reduction of capital and labor income taxes.
} 
commonly called "ideological biases," differ in sign and size across individuals. The parties, whose prior information is identical, know only the distribution of the bias. The interesting aspect of this framework is its incorporation of uncertainty regarding who votes for which party. Neither party would know for certain what platform, and offered by which party, can muster the majority of votes. If this uncertainty is "large enough", an equilibrium exists for a simultaneous and noncooperative game in party platforms between the two parties; see Lindbeck and Weibull (1987). Moreover, this equilibrium is unique, with both parties converging to the same platform.

The third model we study is the more sophisticated political competition model of Roemer (2001) and his equilibrium solution concept of PUNE. In this setting, two political parties compete in an election. Both parties simultaneously commit themselves to the policy they will implement if elected. Individuals vote for the party whose policy they prefer; however, some electoral uncertainty exists due to randomness in voters' turnout. Parties choose their platform through a bargaining process between two factions: the "opportunists" and the "militants". Opportunists care only about the probability of winning the election, while militants are only interested in the announced policies. The policy adopted by a party is required to be on the Pareto frontier between the two factions. In other words, no feasible alternative is unanimously preferred to the current policy. This defines the parties' preferences over policies in the political competition game; a PUNE is simply a Nash equilibrium of this game.

In the economic model we consider, individuals have identical Gormanpolar form preferences over a (non-polluting) numeraire good and the polluting good. The goods are produced by a linear technology subject to constant returns to scale in a competitive environment. This is essentially the setup we used in Cremer et al. (2004a). However, that paper used a traditional majority-voting approach only, and the numerical illustrations were not based on actual empirical data. ${ }^{2}$ Here, we provide numerical solutions for each of

\footnotetext{
${ }^{2}$ See also Cremer et al. (2004b, 2007) who study the determination of a two-dimensional policy comprising a tax and a budgetary rule that specifies the ratio of capital to labor income taxes. These papers, unlike Cremer et al. (2004a), follow a positive approach to the determination of both policy instruments. Cremer et al. (2004b), faced with the non-existence problem, resorts to two sequential voting procedures (with either policy being determined first and the other later), as well as the Shepsle procedure, to arrive at a political equilibrium. They find that (in most cases) the equilibrium corresponds to the preferences of the "median individual". This includes the prediction that all tax revenues must be rebated solely through either wage subsidies or capital income subsidies. Actual policies, of course, never display such a knife-edge property. Cremer et al. (2007) use the PUNE approach. This gets rid of the knife-edge property of the budgetary rule, but viable equilibria continue
} 
the three political frameworks we consider based on an economic model that is calibrated for the US economy. Using data from the 2001 Panel Study for Income Dynamics Survey, we estimate a bivariate lognormal distribution for labor and asset incomes from the sample of the 6,877 households who reported a nonzero income (whether labor or asset incomes) for the year 2000.

We consider an aggregate of energy-related consumption goods to represent the polluting good (fuel oil, gasoline, natural gas, kerosene, LPG and electricity). To calibrate the demand function, we assume a price elasticity of demand of -0.30 , an income elasticity of demand of 0.41 , and a ratio of average expenditure on energy to average income of $0.056 .{ }^{3}$ Pollution is measured by carbon dioxide emissions, which are determined according to the carbon content of each component and appropriately weighted. Our estimate of the marginal social damage of the polluting good is based on a value of $\$ 50$ for the social marginal cost of a ton of carbon (based on the estimates reported by the EPA). ${ }^{4}$

We show that the majority-voting equilibrium calls for a reduction in current energy prices that ranges from $33 \%$ to $91 \%$ (all prices are stated relative to the price of consumption goods). The failure of the median-voter model to predict the existence of environmental taxes is one message of this paper. As such, it lends further support to the empirical literature that questions the predictive power of the median-voter model, as represented by the median-income citizen or voter. Romer and Rosenthal (1979), Mathis and Zech (1989), Turnbull and Mitias (1999), and Turnbull and Geon (2006), among others, have argued that the median-voter model is not a good representation of political equilibrium when political decision making is at governmental levels above municipalities and school districts. ${ }^{5}$.

Unlike majority-equilibrium voting, the probabilistic-voting and PUNE

to be characterized by subsidies.

${ }^{3}$ The elasticity figures are from the literature, see footnote 15 below. The figure for energy consumption to income ratio is from the Consumer Expenditure Surveys, 2002.

${ }^{4}$ On the EPA website: http://www.epa.gov/oppt/epp/guidance/top20faqexterchart.htm

${ }^{5}$ Romer and Rosenthal (1979) reviewed the empirical studies that existed until then to determine if government expenditures could be explained by the preferences of the median voter, and answered the question negatively. Mathis and Zech (1989) use data on 36 Pennsylvania municipalities that voted for a home rule charter (a multi-dimensional issue) during the 70s. They concluded that the median-voter hypothesis is not appropriate for prediction when it comes to multi-dimensional issues. Turnbull and Mitias (1999) examined county spending in five Midwestern states and also rejected the median-voter hypothesis. Turnbull and Geon (2006) found that restricting home rule (i.e. imposing constitutional constraints on local government behavior) increases the likelihood of the applicability of the median-voter equilibrium. 
models predict increasing the current energy taxes. The former calls for an increase in the current energy prices of $10 \%$ to $120 \%$, and the latter implies increases that range from $63 \%$ to $122 \%$ (all expressed relative to consumption goods). To put these predictions in perspective, observe that in 2000 the combined federal and states' taxes averaged to 37 cents per gallon constituting $25.2 \%$ of the average price of gasoline. When expressed relative to the consumer price of consumption goods, the existing tax rate is about $17.4 \%$. (In 2006, with the rise of gasoline prices, these figures fell to $15.6 \%$ and $7.8 \%){ }^{6}$.

\section{The model}

Consider an economy with two goods: a clean numeraire good and a polluting good $y$. Production technologies are linear, and the producer price of $y$ is set at one. Consumers have identical Gorman-polar form preferences given by

$$
v(q, I, Y)=a(q)+b(q) I-\varphi(Y)
$$

where $q$ denotes the consumer price of $y, I$ is disposable income, and $Y$ is aggregate consumption of $y$. The polluting good creates a negative "atmosphere externality", $\varphi(Y)$, with $\varphi^{\prime}(Y)>0$, and $\varphi^{\prime \prime}(Y)>0$. We further assume that $a^{\prime}(q) \leq 0$ and $b^{\prime}(q) \leq 0$. The demand for $y$ is given by

$$
y(q)=-\frac{\partial v / \partial q}{\partial v / \partial I}=c(q)+d(q) I(\theta)
$$

where $c(q)=-a^{\prime}(q) / b(q)>0$, and $d(q)=-b^{\prime}(q) / b(q) \geq 0$. The demand for $y$ is thus increasing in income except in the limiting case of $b^{\prime}(q)=0$ where we have quasi-linear preferences.

Individuals are identified by a two-dimensional type parameter $\theta$ which is distributed over $H \subset \mathbb{R}_{+}^{2}$, according to $F(\theta)$, with total population size normalized at one. An individual of type $\theta$ has exogenous capital and labor incomes, $r(\theta)$ and $w(\theta)$, and a total (before tax) income of $m(\theta)=r(\theta)+w(\theta)$. Aggregate consumption of the polluting good is then equal to

$$
Y=\int_{H} y(q) d F(\theta)=\bar{y}(q)
$$

so that total and average consumption levels are equal. A single individual's consumption of $y$ does not impact $Y$.

\footnotetext{
${ }^{6}$ See the Calibration Section below.
} 
The proceeds $R(q)=(q-1) \bar{y}(q)$ of the "pollution tax" are refunded through reductions in labor and capital income taxes. ${ }^{7}$ For simplicity, pre-existing taxes are not explicitly included. Refunds are then proportional to capital and labor incomes, at rates $g_{r}$ and $g_{w}$ that may differ from each other (but are restricted to be of the same sign). Consequently, the disposable income of individual $\theta$ is given by

$$
I(\theta)=\left(1+g_{r}\right) r(\theta)+\left(1+g_{w}\right) w(\theta) .
$$

The government's budget constraint implies

$$
R(q) \equiv(q-1) \bar{y}(q)=g_{r} \bar{r}+g_{w} \bar{w},
$$

where $\bar{r}$ and $\bar{w}$ denote the average capital and labor incomes. Let

$$
\alpha=\frac{g_{w} \bar{w}}{R(q)}=1-\frac{g_{r} \bar{r}}{R(q)},
$$

denote the proportion of tax proceeds that are refunded on the basis of wage incomes. We shall refer to this parameter as the "budgetary rule". The taxcum-refund policy is completely characterized by the two parameters $q$ and $\alpha .^{8}$ Throughout this paper we assume that the value of $\alpha$ is predetermined and concentrate on the determination of $q$ through the political process.

With $\alpha$ given, we have a one dimensional problem (the determination of $q)$ that has a majority-voting equilibrium and whose value one can calculate. ${ }^{9}$ Our main focus lies, however, in contrasting the traditional median-voter approach with two alternative models of the political process: the probabilistic voting model and Roemer's model of political competition with the "Party Unanimity Nash Equilibrium" (PUNE) as equilibrium concept.

Before turning to the description of these two approaches, we first establish a benchmark for the value of the environmental tax and then describe the individual preferences of voters for this tax.

\subsection{Optimal tax benchmark}

To obtain the utilitarian optimum, write the sum of utilities as

$$
W=\int_{H} v(q, I(\theta), Y) d F(\theta)=a(q)+b(q) \bar{I}-\varphi(Y),
$$

\footnotetext{
${ }^{7}$ The tax $(q-1)$ is endogenous and not a priori restricted to be positive. Consequently, negative "refunds" are not ruled out.

${ }^{8}$ To ensure that $g_{w}$ and $g_{r}$ are of the same sign, we set $\alpha \in[0,1]$.

${ }^{9}$ Cremer et al. (2004a) prove existence as long as the income elasticity of demand for $y$ does not exceed a limiting number.
} 
where $\bar{I}=\left(1+g_{r}\right) \bar{r}+\left(1+g_{w}\right) \bar{w}=\bar{r}+\bar{w}+R(q)$. Incorporating the government's budget constraint (5) in $W$, one obtains

$$
W=a(q)+b(q)[\bar{m}+R(q)]-\varphi(\bar{y}(q))
$$

where $\bar{m}=\bar{r}+\bar{w}$ denotes the average aggregate income. Expression (7) is independent of $\alpha$ because, with Gorman-polar form preferences and a utilitarian objective, redistributive considerations do not matter: all individuals have a constant marginal utility of income equal to $b(q)$. Maximizing $W$ with respect to $q$, assuming an interior optimum, yields

$$
q^{F B}-1=\frac{\varphi^{\prime}\left(Y^{F B}\right)}{b\left(q^{F B}\right)}>0,
$$

where $Y^{F B}=\bar{y}\left(q^{F B}\right)$, and superscript $F B$ stands for first-best. ${ }^{10}$ Thus $\left(q^{F B}-\right.$ 1 ) is determined according to the traditional Pigouvian rule and equals the marginal social damage.

\subsection{The $\theta$-type voter's preferences for $q$}

Incorporate the government's budget constraint (5) in the $\theta$-type's indirect utility function (1), using also equations (4) and (6), to obtain the reduced indirect utility function,

$$
V(q, \alpha, \theta)=a(q)+b(q)[m(\theta)+\delta(\alpha, \theta) R(q)]-\varphi(\bar{y}(q))
$$

where

$$
\delta(\theta, \alpha) \equiv(1-\alpha) \frac{r}{\bar{r}}+\alpha \frac{w}{\bar{w}}
$$

The function $\delta(\theta, \alpha)$ specifies the proportion of total tax receipts that individual $\theta$ obtains in refunds. ${ }^{11}$ This proportion plays a crucial role in determining a voter's preferences over $q$. It is also the only channel through which $\alpha$ affects $V(q, \alpha, \theta)$.

Denote $\theta$ 's most-preferred value of $q$ conditional on $\alpha$ by $q^{*}(\theta, \alpha)$. Lemma 1 which is proved in the Appendix, characterizes $q^{*}(\theta, \alpha)$ :

\footnotetext{
${ }^{10}$ Cremer et al. (2004a) prove that the second-order condition for this problem is satisfied: the problem has a unique solution at $q^{F B}$, with the first derivative of $W$ being always positive to the left of $q^{F B}$ and negative to its right. This implies that $W$ is increasing everywhere to the left of $q^{F B}$ and decreasing to its right, with $q^{F B}$ yielding the global maximum.

${ }^{11}$ The expression remains valid when $q<1$ so that $R(q)<0$. The function $\delta(\theta, \alpha)$ then shows the ratio of $\theta$ 's income tax payments to the price subsidy he receives from the consumption of the polluting good.
} 
Lemma 1 (i) Let $\widetilde{q}(\delta, m)=\arg \max _{q}[a(q)+m b(q)+\delta b(q) R(q)-\varphi(\bar{y}(q))]$. Then $q^{*}(\theta, \alpha)=\widetilde{q}(\delta(\theta, \alpha), m(\theta))$, so that $q^{*}$ depends on $\alpha$ only through $\delta$.

(ii)

$$
\begin{aligned}
\frac{\partial \widetilde{q}}{\partial \delta} & =\frac{b(q)\left[R^{\prime}(q)-d(q) R(q)\right]}{-\partial^{2} V(q, \alpha, \theta) / \partial q^{2}} \\
\frac{\partial \widetilde{q}}{\partial m} & =\frac{b^{\prime}(q)}{-\partial^{2} V(q, \alpha, \theta) / \partial q^{2}} \leq 0
\end{aligned}
$$

(iii) In the special case of quasi-linear preferences, and assuming $R^{\prime}(q)>0$, $\widetilde{q}(\delta, m)$ increases with $\delta$ so that $q^{*}(\theta, \alpha)$ is increasing in $r$ and $w$ (for a given value of $\alpha)$. Furthermore, we have

$$
\begin{aligned}
& \delta(\theta, \alpha)=1 \Rightarrow q^{*}(\theta, \alpha)=q^{F B}>1, \\
& \delta(\theta, \alpha)>1 \Rightarrow q^{*}(\theta, \alpha)>q^{F B}>1, \\
& \delta(\theta, \alpha)<1 \Rightarrow q^{*}(\theta, \alpha)<q^{F B} \text { so that } q^{*}(\theta, \alpha) \gtrless 1 .
\end{aligned}
$$

This lemma signifies the importance of $\delta$ in determining if an individual $\theta$ prefers the polluting good to be taxed or subsidized, and in the case of a tax, whether the tax should exceed or fall short of the Pigouvian tax. This is best seen with quasi-linear preferences. In this case, if $\delta=1$, the individual receives a refund precisely equal to his tax payment. With no net monetary costs or benefits, his most-preferred tax is the Pigouvian one. If $\delta>1$, taxation of the polluting good confers a net monetary benefit on the individual, enticing him to want a tax larger than the Pigouvian tax. Finally, if $\delta<1$, taxation of the polluting good results in a net monetary loss for the individual. He would then want a lower than Pigouvian tax. Whereas in the first two cases the individual necessarily prefers a tax to a subsidy, in the third case he may prefer either one. In particular, he prefers a subsidy to a tax (i.e., $q^{*}<1$ ), if his net monetary loss exceeds the environmental benefit that results from a positive tax.

The presence of income effects complicates this picture. It implies that $\widetilde{q}$ moves negatively with $w$ and $r$ through (12). It also negatively affects the size of $\partial \widetilde{q} / \partial \delta$ and may even make $\partial \widetilde{q} / \partial \delta$ negative. The upshot is that the presence of income effects has a dampening effect on a taxpayer's most-desired tax level (as compared to the case with no income effects).

\section{Political equilibrium}

In the remainder of the paper, we study the determination of $q$ through the political process for a given level of $\alpha$. We look at three political solution 
concepts. The first one is majority voting - a well known solution concept that does not require any introductory comments. The second is the probabilisticvoting model, which is somewhat less known; see Persson and Tabellini (2000). The third concept, namely, "Party Unanimity Nash Equilibrium" (PUNE), is not that widely known; see Roemer (2001). To make the paper self-contained, we give a brief presentation of these latter two equilibrium concepts.

\subsection{Probabilistic voting}

With probabilistic voting, parties are purely office-motivated. Citizens, on the other hand, care not only for policies per se but also for the political parties that propose the policies. That is, they may strictly prefer one party to another even if the parties propose identical policies. Preferences for a particular party, or what is commonly called "ideological biases," differ in sign and size across individuals. More precisely, one's "type" is defined on the basis of his characteristics other than his ideological bias (i.e., his wage and capital income in our setting). Hence any given type $\theta$ may have biased and unbiased voters. The distribution of biased (and unbiased) voters may differ across types. The parties know only the distribution of the bias, where their prior information is identical.

This setting implies some degree of uncertainty regarding who votes for which party. Neither party would then know for certain what platform, and offered by which party, can muster the majority of votes. Lindbeck and Weibull (1987) show that if this uncertainty is "large enough", i.e. if the variance of the bias distribution that causes it is "large enough", an equilibrium exists for a simultaneous and noncooperative game in party platforms between the two parties. They also prove that this equilibrium is unique, with both parties converging to the same platform. The platform maximizes a weighted sum of the citizens' utilities,

$$
\int_{H} \phi(\theta) V(q, \alpha, \theta) d F(\theta),
$$

where $\phi(\theta)$ denotes the density of unbiased citizens among those of type $\theta$. The intuition for this result is that since both parties propose the same policy, the only voters who matter for winning an election are the unbiased swing voters who are indifferent between voting for one party or the other. Thus, within a type, only the density of the unbiased citizens matters, and parties court these swing voters. 


\subsection{Party Unanimity Nash Equilibrium}

Two political parties compete in an election. Both parties simultaneously commit themselves to the policy they will implement if elected. Individuals vote for the party whose policy they prefer; turnout is random, however, which causes some electoral uncertainty (as in probabilistic voting models). Parties choose their platform through a bargaining process between two factions: the "opportunists" and the "militants". Opportunists care only about the probability of winning the election, while militants are only interested in the announced policies. The policy adopted by a party is required to be on the Pareto frontier between the two factions. In other words, no feasible alternative is unanimously preferred to the current policy. This defines the parties' preferences over policies in the political competition game; a PUNE is simply a Nash equilibrium of this game. Note that it is the unanimity requirement that makes deviations difficult, providing the crucial requirement that ensures the existence of a (pure strategy) equilibrium.

To provide a formal definition of a PUNE, index the parties by $i=L, R$, where $L$ stands for the "Left" (Democrats in our calibrations) and $R$ stands for the "Right" (Republicans in our calibrations). The objective function of the militants is given by

$$
v_{i}(q ; \alpha)=\int_{H} \omega_{i}(\theta) V(q, \alpha, \theta) d F(\theta), \quad i=D, R,
$$

where $\omega_{i}(\theta)$ is the weight attributed by party $i$ 's militants to individuals of type $\theta$. The probability that party $i$ wins the election is denoted by $\pi_{i}\left(q_{i}, q_{j} ; \alpha\right)$; where $q_{i}$ and $q_{j}, i \neq j=L, R$, denote the prices proposed by the two parties. This probability is the objective function of the opportunists. It is increasing in the share of voters preferring $q_{i}$ to $q_{j}$, and is determined by assuming that each individual $\theta$ participates in the election with some probability. Further, assume that when both parties offer the same policy, $\pi_{L}=\pi_{R}=1 / 2$. We have:

Definition 1 A Party Unanimity Nash Equilibrium is a pair of policies $q_{L}, q_{R} \in$ $\mathbb{R}_{+}$such that for each $i, j=L, R, i \neq j$, no other policy $q \in \mathbb{R}_{+}$has the property that, given $q_{j}, v_{i}(q ; \alpha) \geq v_{i}\left(q_{i} ; \alpha\right)$ and $\pi_{i}\left(q, q_{j} ; \alpha\right) \geq \pi_{i}\left(q_{i}, q_{j} ; \alpha\right)$, where at least one inequality is strict.

The most striking difference between PUNEs and probabilistic-voting equilibria is the absence of convergence to the same platform in the case of PUNEs. Divergence between equilibrium platforms is a well-documented empirical result; see, for instance, Alesina and Rosenthal (1995) and Poole and Rosenthal (1984a,1984b) for the US, Hofferbert and Budge (1992) for the UK, and Hofferbert and Klingemann (1990) for Germany. 


\section{Data and calibrations}

Our objective is not just to characterize the political equilibria but also to provide (at least illustrative) numerical estimates. To achieve this, we have to specify and estimate the voters' preferences and the distribution of incomes. Moreover, to compute PUNEs, we have to determine the militants' preferences in each party (i.e., the weights $\omega_{i}(\theta)$ that they use) and to construct the winning probability functions $\pi_{i}$ (based on the probability that a voter of a particular type would participate in the election). We explain below the procedures we have used for these calculations. In the case of probabilistic voting, one ideally wants data on the proportion of unbiased voters among citizens with different income levels. Unable to find such data, we use a procedure explained in Section 5.3 below.

Data on spending patterns and incomes are obtained from the 2001 Panel Study for Income Dynamics Survey. The survey consists of a total of 7,406 households, of which we retain the 6,877 households who report a nonzero (total) income in 2000. ${ }^{12}$ We fit a bivariate lognormal distribution for labor and asset incomes to this truncated sample (while using the weights that the survey assigns to each household.) ${ }^{13}$

To calculate the numerical values for the parameters of the individuals' utility function $a(q)$ and $b(q)$, we first calibrate the parameters of the demand function for energy. Given the Gorman-polar specification, we have $y(q)=$ $-a^{\prime}(q) / b(q)-\left[b^{\prime}(q) / b(q)\right] I$. To be able to gauge the importance of the income effect through a single parameter, we assume that $b(q)=1-\beta q$. This enables us to rewrite the demand function as

$$
y(q)=\frac{-a^{\prime}(q)}{1-\beta q}+\frac{\beta}{1-\beta q} I .
$$

To make things simple, we further assume that the first expression in the right-hand side of above is linear in price and includes a constant term. ${ }^{14}$ In

\footnotetext{
${ }^{12}$ Specifically, we calculate labor income as the sum of labor income and the labor part of business income of the Head of the household and his spouse. To calculate asset income, we take the family's reported income and subtract the calculated labor income, transfer income, social security income, and the Head's farm income.

${ }^{13}$ Recall that our model postulates that voters differ only in two dimensions: labor and asset incomes. The mean, median and standard deviation are $\$ 50,294, \$ 36,100$ and $\$ 64,825$ for labor incomes, and $\$ 9,632, \$ 433$, and $\$ 42,838$ for asset incomes. The correlation coefficient between labor and asset incomes is 0.163 - a figure in line with the numerical calculation of Champernowne and Cowell (1998) who report a correlation coefficient of 0.135 using 1985 PSID data.

${ }^{14}$ See the Appendix for details.
} 
order to calculate the three parameters of the resulting equation, we must first specify the nature of the polluting good. We take this to be "energy" and define it as an aggregate of energy-related consumption goods (fuel oil, gasoline, natural gas, kerosene, LPG, and electricity). We use three pieces of information to pin down the values of the three parameters: the marginal propensity to consume energy out of income (which on the basis of our data is $2.25 \%$, implying a value of 0.405 for the income elasticity of demand for the "average consumer"), long-run price elasticity of demand (equal to -0.30), and the ratio of average expenditure on energy to average income (equal to 0.0555 , with an average income of $\$ 59,926) .{ }^{15}$ All our calculations are based on the assumption that the relative consumer price of a "unit" of energy is equal to one. This normalization implies that all the predicted tax rates are in addition to current taxes.

We assume that the disutility from pollution is given by

$$
\varphi(Y)=e^{h+k Y} .
$$

We take the pollution generated by energy to be the release of carbon dioxide into the atmosphere. The carbon content of the polluting good is found according to the carbon content of each appropriately-weighted component. Using a value of $\$ 50$ for the social marginal cost of a ton of carbon, ${ }^{16}$ we calculate the marginal social damage of one unit of the polluting good. This translates into a tax rate of about $10 \%$ on the polluting good. To set $h$ and $k$ we choose the least convex function compatible with a Pigouvian tax of $10 \%$ and a positive value for every household's most-preferred $q$.

To calculate the PUNE tax rate, we must determine the weights that the two parties' militants assign to the preferences of each voter, $\omega_{i}(\theta) i=L, R$. We use a modified version of Bartels' weights (2002), found by regressing the observed roll call vote of senators on their constituents' opinion (among other variables) weighted by the income of the constituents, for these. Running separate regressions for Democrats and Republicans, he estimates that the

\footnotetext{
${ }^{15}$ The -0.30 figure is based on existing estimates for the long run price elasticity of consumer demand for energy. These vary from -0.35 to -0.15 ; see Branch (1993), Filippini (1999), Gately and Huntington (2001), Hodge (1999), National Institute of Economics and Industry Research (2002), and Ninomiya (2002). The 0.0555 figure is found from the Consumer Expenditure Surveys, 2002, which report a value of 0.064 for the ratio of average energy consumption to average annual expenditures; and 0.8667 for the ratio of average net-of-tax to average gross-of-tax income. The $\$ 59,926$ value for average income comes from the 2001 PSID data.

${ }^{16}$ This is within the range of estimated values of $\$ 5.5$ to $\$ 187$ on the EPA website. See http://www.epa.gov/oppt/epp/guidance/top20faqexterchart.htm .
} 
weight given to an individual with income $I$ is $-0.02+0.04 I$ for Democrats and $-0.86+0.099 I$ for Republicans. We modify these weights in two ways. First, Bartels uses income data from 1990, while we use 2000. Consequently, the coefficients on incomes have to be deflated. We do this by using the variation in the Consumer Price Index between 1990 and 2000. Consequently, we divide 0.04 and 0.099 above by 1.278. Second, we restrict the weights to be nonnegative. For the Democrats, we simply set the constant part of $\omega_{L}$ at zero (instead of -0.02); and for the Republicans, we use $\max \left[0, \omega_{R}\right]$ rather than $\omega_{R}$. We obtain

$$
\begin{aligned}
& \omega_{L}=0.031(w+r), \\
& \omega_{R}=\max [0,-0.86+0.077(w+r)],
\end{aligned}
$$

which we use in the calculation of the PUNE tax rates.

To calculate the probability that a particular voter participates in the election, we continue to rely on Bartels (2002), using his regression of turnout on income. As with the voters' weights, we modify his results (as reported in his Table A6) on the basis of the consumer price indices for 1990 and 2000. Moreover, given the linear specification between turnout and income, some precautions are necessary to ensure the probabilities are between 0 and 1 . The average turnout in the economy is then $72 \%$, and the "average individual" (a person with average income) votes with a probability of $75.5 \%$.

To put the predictions of our three political economy models in perspective, we also calculate the current "tax rate" on energy in the US. Given that the bulk of energy taxes in the US are fuel taxes, we approximate this concept by the tax rate on gasoline. The Monthly Motor Fuel Reported by States (U.S. Department of Transportation, 1999) reports the average gasoline tax in the US in March 2000 was 37 cents per gallon (consisting of a federal tax of 18.4 cents and the weighted average of State taxes that ranged from 7.5 cents in Georgia to 29.7 in New York). The U.S. Department of Transportation also reports a weighted average price of $\$ 1.47$ per gallon of gasoline in $2000 .{ }^{17}$ These figures translate into a tax rate of $25.2 \%$. We also calculate, on the basis of "Comparison of state and local taxes" (http://www.taxadmin.org/fta/rate/sl_sales.html), the weighted average of sales tax rates in the US at $7.8 \%$. Consequently, in the U.S., the relative tax rate between gasoline and other goods was about $17.4 \%$ in the year $2000 .{ }^{18}$

\footnotetext{
${ }^{17}$ On the US Department of Transportation website, see http://www.fhwa.dot.gov/ohim/hs00/in5.htm and http://www.fhwa.dot.gov/ohim/mmfr/mmfrpage.htm.

${ }^{18}$ With the rise in gasoline prices during the past few years, the U.S. tax rates have
} 
A final observation is in order. With the current consumer price of energy normalized at 1 , and $q=1.1$ as the optimal price, we are assuming that none of the existing energy taxes are levied for environmental concerns. This is of course arbitrary, as any other assumption would be. All that one can observe is a tax rate. What portion of it is levied for what purpose can never be known. Our working assumption is based on the fact that the gasoline tax in the US was introduced primarily for the purpose of financing road constructions and upkeep, and earmarked for the highway trust fund. Moreover, environmental concerns are rather new, while energy taxes have been in place for some time now. In fact, notwithstanding the recent environmental concerns, the US energy tax rates have been falling sharply over the past few years (caused by the huge increases in the producer price of energy). Observe also that energy taxes are particularly low in the US, as compared to most other industrialized countries in Europe, as well as Canada and Japan. Finally, to the extent that gasoline prices are raised by processing additives that are mandated for environmental objectives, the added mark ups reflect "implicit" environmental taxes but they are included in the producer price and do not raise tax revenues.

\section{Results}

We now determine the equilibrium tax rates for our three political economy models, starting with the majority-voting.

\subsection{The majority-voting equilibrium value of $q$}

The preferences obtained from our calibrations are single-peaked in $q$, implying existence of a classical, Downsian majority-voting equilibrium, given by the median voter's most-preferred value of $q$. In the special case of quasi-linear preferences, it is easy to rank individuals according to $q^{*}(\theta, \alpha)$, since Lemma 1 , part (iii) has established that $q^{*}(\theta, \alpha)$ is increasing in $\delta$. Ranking is more difficult in the presence of income effects, because as shown in Lemma 1,

declined. Using the same source, the average gasoline tax and price in the U.S. in September 2006 were 39 cents and $\$ 2.506$ per gallon of gasoline. These translate into a tax rate of $15.6 \%$, equal to $7.8 \%$ when expressed relative to the consumer price of consumption goods.

The American Petroleum Institute (API, 2007) reports a higher average tax rate equal to 45.8 cents for March 2007. The difference with the U.S. Department of Transportaion figures is due to API's inclusion of "other State taxes," which include "applicable sales taxes, gross receipts taxes, oil inspection fees, underground storage tank fees and other miscellaneous environmental fees". Using API's figures the current gasoline tax rate is $18.3 \%$, equal to $10.5 \%$ when expressed relative to the consumer price of consumption goods. 
$q^{*}(\theta, \alpha)$ also depends (negatively) on $m(\theta)$. We have computed numerically the majority-voting equilibrium value of $q$, denoted by $q^{M C}$, and we report the values of $q^{M C}-1$ as a function of $\alpha$ in the fourth row of Table 1. The superscript $M C$ stands for "median citizen" defined on the basis of the citizens' preferences for $q$. Specifically, $50 \%$ of the population prefer a $q$ higher than $q^{M C}$ and another $50 \%$ prefer a $q$ lower than $q^{M C}$. The case for which $g_{w}=g_{r}$, i.e. when taxes or subsidies are proportional to total income regardless of their source, is represented by $\alpha=0.839$. With our calibration, the direct income effects are "small" enough, and the correlation between $w$ and $r$ is large enough, to ensure that richer people have a higher most-preferred value of $q$. Consequently, since the median wage and the median capital income are smaller than their average counterparts, $q^{M C}<q^{F B}$ for all values of $\alpha$.

The determination of $q^{M C}$ is based on the assumption that all citizens participate in the election with the same probability. As we noted in Section 4, however, this is not the case empirically. Instead, turnout probability increases with total income. With small income effects, this suggests that more than $50 \%$ of voters, as opposed to citizens, prefer $q$ to be higher than $q^{M C}$. We can then determine a second value for the majority-voting equilibrium $q$ which takes the turnout probabilities into account. Denote this equilibrium by $q^{M V}$ ( $M V$ stands for "median voter"). We obtain that $q^{M V}>q^{M C}$, and also in Table 1 report the solutions for $q^{M V}-1$, conditional on different values of $\alpha$. Note that, as with $q^{M C}$, for all values of $0 \leqq \alpha \leqq 1, q^{M V}<q^{F B}$. This occurs because adjusting for turnout probabilities leaves the ratio of median income to average income well below one, for both wage earners and capital owners. ${ }^{19}$ Observe also that $q^{M C}$ and $q^{M V}$ increase with $\alpha$. In the absence of income effects, a necessary and sufficient condition for this positive relationship is that wage incomes are less positively skewed than capital incomes, so that the gap between median and average is lower for wage income than for capital income. We then find that the income effects present in our calibration are not large enough to reverse this comparative statics result.

Table 1: Desired energy tax rates in addition to current rates

\footnotetext{
${ }^{19}$ Specifically, the ratio of median income to average income increases from $61 \%$ (for the median citizen) to $73 \%$ (for median voter) in the case of wage incomes, and from $22 \%$ (median citizen) to $26 \%$ (median voter) for capital incomes.
} 


\begin{tabular}{lrrrrrr}
\hline Values of $\alpha$ & .000 & .250 & .500 & .750 & .839 & 1.000 \\
\hline $\begin{array}{l}\text { Welfare maximizing: } \\
\text { Majority voting: }\end{array}$ & 10.0 & 10.0 & 10.0 & 10.0 & 10.0 & 10.0 \\
$\quad$-uniform voting prob. & -91.0 & -82.0 & -67.0 & -53.9 & -51.0 & -50.7 \\
$\quad$-nonuniform voting prob. & -90.5 & -79.4 & -58.6 & -38.5 & -35.7 & -33.4 \\
PUNEs: & & & & & & \\
$\quad$-Democrats & 119.8 & 112.3 & 102.1 & 87.2 & 80.0 & 63.4 \\
$\quad$-Republicans & 122.1 & 114.9 & 104.8 & 90.0 & 82.8 & 66.0 \\
Probabilistic voting: & & & & & & \\
$\quad$-same weight & 10.0 & 10.0 & 10.0 & 10.0 & 10.0 & 10.0 \\
$\quad$-with turnout & 39.1 & 37.0 & 34.9 & 32.7 & 31.9 & 30.5 \\
$\quad$-affine no intercept & 119.8 & 112.3 & 102.1 & 87.2 & 80.0 & 63.4 \\
$\quad$-affine small intercept & 118.5 & 110.9 & 100.6 & 85.6 & 78.5 & 62.0 \\
$\quad$-affine median intercept & 115.9 & 108.2 & 97.7 & 82.6 & 75.5 & 59.3 \\
$\quad$-affine large intercept & 109.0 & 100.8 & 90.0 & 74.9 & 68.0 & 52.7 \\
\hline
\end{tabular}

\subsection{The PUNEs}

We now turn to the determination of PUNE tax rates in the voting game over $q$. This requires us to examine the militants' and the opportunists' preferences for $q$ within each party. Consider first the utility of the militants, a weighted sum of the citizens' utilities. Let $q_{L}^{*}$ and $q_{R}^{*}$ denote the most-preferred values of $q$ for the militants of the Left and the Right party (Democrats and Republicans). Observe that, with single-peaked preferences, the utility of militants in party $i=L, R$ increases as party $i$ 's proposed $q$ moves closer to its blisspoint $q_{i}^{*}$. Moreover, given that the weights used by both parties' militants are increasing in total income, that the Right party's militants put a higher weight on the utility of the richer individuals (as compared to the Left party's militants) and no weight on poor individuals, and that income effects are small, we obtain $q^{F B}<q_{L}^{*}<q_{R}^{*} .^{20}$

Next, consider the utility of the opportunists, which depends upon two important properties of our calibrated model. First, direct income effects are "small" enough to ensure that $q^{*}(\theta, \alpha)=\widetilde{q}(\delta(\theta, \alpha), m(\theta))$ is increasing in $\delta$. Second, for a given $q_{R}$, an increase in $q_{L}$ increases the proportion of the electorate who prefer $q_{L}$ to $q_{R}$. Yet, for a given $q_{L}$, an increase in $q_{R}$ lowers the proportion of the electorate who prefer $q_{R}$ to $q_{L}$. We are now able to show:

\footnotetext{
${ }^{20}$ Recall that $q^{F B}$ is the most-preferred value of $q$ under a utilitarian social welfare function that sums the utilities of the entire population (with everyone receiving the same weight).
} 
Result 1 The set of PUNEs consists of all $\left(q_{L}, q_{R}\right)$ given by

$$
q_{L}^{*} \leq q_{L}<q_{R} \leq q_{R}^{*},
$$

and the point $q_{L}^{*}=q_{L}=q_{R}<q_{R}^{*}$.

Proof. To prove that any such configuration is a PUNE, consider the implications of deviating from it. Observe first that the most-preferred policies of the two parties' militants $\left(q_{L}^{*}, q_{R}^{*}\right)$ constitute, by definition, a PUNE: all deviations from this pair of policy proposals would decrease the utility of the militants in both parties. Now take any $\left(q_{L}, q_{R}\right)$ such that (17) holds with $q_{L}^{*}<q_{L}$, and consider how the factions in party $\mathrm{L}$ react to a decrease in $q_{L}$. This reduction would be supported by L's militants, as it brings them closer to their blisspoint. On the other hand, the opportunists in party L would oppose this move: It decreases the party's probability of winning by increasing the proportion of citizens who prefer $q_{L}$ over $q_{R}$. Similarly, take any $\left(q_{L}, q_{R}\right)$ such that (17) holds with $q_{R}<q_{R}^{*}$, and consider party R's factions: Militants would like to increase $q_{R}$, while opportunists would prefer to decrease it.

Observe now that no configuration with $q_{L}^{*}<q_{L}=q_{R}$ can be a PUNE. Starting from such a configuration, party L can increase both the utility of the militants and the party's probability of winning by decreasing $q_{L}$ (doing so results in $q^{M V}<q_{L}^{*}<q_{L}<q_{R}$, so that $\pi_{L}$ jumps from $1 / 2$ to a strictly higher value). Finally, $q_{L}^{*}=q_{L}=q_{R}$ is also a PUNE: L's militants oppose any deviation from this point, while R's opportunists block their party's militants' wish to increase $q_{R}$ (such a change would drop the party's probability of winning from $1 / 2$ discontinuously).

To prove that other configurations are not PUNEs, one must again consider the implications of deviations from all such configurations. As an example, consider $q_{L} \leq q_{L}^{*}<q_{R} \leq q_{R}^{*}$. In this case, both the militants and the opportunists in the Left party want to increase $q_{L}$. Similar arguments rule out all other configurations.

Observe first that the turnout probabilities play no role in the above result; they affect the probability of winning for each PUNE but not the location of the PUNEs. This remains true even if both parties use different turnout probabilities (as long as every voter has a strictly positive turnout probability). Moreover, since $q^{M C}<q^{M V}<q^{F B}<q_{L}^{*} \leq q_{L}<q_{R} \leq q_{R}^{*}{ }^{21}$ the Left party

\footnotetext{
${ }^{21}$ Observe that $q^{M V}$ is affected by the turnout probabilities, so that the fact that the PUNEs call for taxes that are higher than (the subsidy) $q^{M V}$ depends on turnout probabilities. For instance, this comparison wouldn't hold if everybody except high income citizens had a positive but negligible turnout.
} 
always has a greater than $50 \%$ probability of winning the elections. Moreover, the PUNEs always entail a higher-than-Pigouvian tax on the polluting good. Table 1 reports the Left and the Right parties' militants' most-preferred values of $q-1$ for different values of $\alpha$; the set of one-dimensional PUNE tax rates consist of all $q_{L}-1<q_{R}-1$ that lie between these reported tax rates. Three observations follow from these numbers and the reported values for $q^{M V}-1$ and $q^{M C}-1$, the majority-voting equilibrium values of $q$ (adjusted and unadjusted for turnout probabilities).

First, regardless of the value of $\alpha$, PUNEs entail a tax, while the majorityequilibrium values of $q$ call for a subsidy $\left(q^{M C}\right.$ as well as $\left.q^{M V}\right)$. That PUNEs entail a tax is due to the fact that the militants in both parties put a higher weight on the utility of richer citizens. That $q^{M C}$ and $q^{M V}$ call for a subsidy is due to the positive skewness of both incomes distributions, with median wage and capital incomes that are substantially lower than their respective average incomes. This observation is particularly important in view of the magnitudes involved. The lowest PUNE tax rate is 0.63. This is a massive tax on the polluting good and is markedly higher than either $q^{M C}-1$ or $q^{M V}-1$, which call for a subsidy. The upshot is that the one-dimensional-policy PUNEs are basically dictated by the preferences of the militants of the two parties and are far removed from the preferences of the majority of the electorate.

Our second observation is that $q_{L}^{*}$ and $q_{R}^{*}$ decrease with $\alpha$, because of the relative skewness of the two income distributions. Recall that $q_{L}^{*}$ and $q_{R}^{*}$ correspond to the most-preferred values of $q$ for individuals who are richer than average. Increasing $\alpha$ implies that the wage income, which is less positively skewed than capital income, is receiving a higher weight. This leads to lower levels of most-preferred taxes for both parties' militants.

Third, $q_{L}^{*}$ and $q_{R}^{*}$ are relatively close in values, particularly considering how far apart they are from the values of $q^{M C}, q^{M V}, q^{F B}$, and the existing energy tax. Recall that the weights used by Democratic militants, $\omega_{L}$, are proportional to income (see equation (15)), while weights used by Republican militants, $\omega_{R}$, increase in income and assign a weight of zero to the poorest individuals (equation (16)). Hence

$$
q_{L}^{*}=\arg \max \int \gamma m(\theta) V(q, \alpha, \theta) d F(\theta),
$$

which is independent of the value of the coefficient on income $\gamma>0$. In turn, this implies that the difference between the Democrats and the Republicans does not come from the fact that Republicans are more sensitive to the income of their constituents (as measured by the slope of the weight function (16)), but rather because, according to Bartels (2002), they do not pay any attention 
to individuals poorer than some threshold level. ${ }^{22}$ The fact that the difference between $q_{L}^{*}$ and $q_{R}^{*}$ is very small, whatever the value of $\alpha$, comes from the observation that the set of voters who receive zero weight from the Republicans is small. This corresponds, from (16), to all individuals with an income lower than $\$ 11,100$, representing $11.4 \%$ of the citizens and $9.1 \%$ of the voters.

\subsection{Probabilistic voting}

In order to compute the probabilistic-voting equilibrium, one needs information on the bias distribution for every citizen type (in our setting, one's type is determined by his capital and labor incomes). In the absence of such information, a possible shortcut is to fix the weights attributed by both parties to each citizen type directly on the basis of some exogenous information. As an example, suppose one believes that the density of unbiased voters is the same at all levels of capital and labor income. This necessitates assigning the same weight to all individual types. In this case, the parties maximize

$$
\int_{H} v(q, I(\theta), Y) d F(\theta)
$$

where $I(\theta)$ is disposable income introduced in equation (1). The probabilistic voting equilibrium proposal consists of the Pigouvian tax level whatever the value of the budgetary rule $\alpha$, as shown in Table 1.

Next assume that the frequency of unbiased voters of type $\theta$ corresponds to this type's probability of turnout. Bartels (2002) calculates this probability to be strictly positive for an individual with zero income and to increase linearly with one's income until it reaches 100\%. Table 1 reports the resulting equilibrium tax rates for each value of $\alpha$. Theses tax rates vary from $30 \%$ to $39 \%$, depending on the value of $\alpha$; they exceed the observed tax rates and the Pigouvian tax (but not by as much as the PUNE tax rates).

A third possibility is to assume that the frequency of unbiased citizens, $\phi(\theta)$, corresponds to the weights attributed to the Left or the Right party's militants in the PUNE model, i.e. to the weights of Bartels (2002). Clearly, using party L's weights (equation (15)), the probabilistic voting equilibrium yields $q_{L}^{*}$. Similarly, using party R's weights (equation (16)), the probabilistic voting equilibrium yields $q_{R}^{*}$. Then using convex combinations of Bartels' weights for Democrats and Republicans, the probabilistic voting equilibria

\footnotetext{
${ }^{22}$ Results of Bartels (2002) suggest that Republicans put a negative weight on the poor's utility. As explained in the calibration section, however, we have imposed a lower bound of zero on the weights.
} 
spans precisely the interval between $q_{L}^{*}$ and $q_{R}^{*}$. This is due to the fact that, as one moves from the Democratic weights to the Republican weights along a convex combination of both, the value of $q$ that maximizes the corresponding weighted sum of utilities increases monotonically from $q_{L}^{*}$ to $q_{R}^{*}$. Thus, any policy played by either party in a PUNE corresponds to a probabilistic voting equilibrium with the density of unbiased voters among type $\theta$ citizens being some convex combination of the Bartels' weights for Democrats and Republicans.

We have seen in the previous section that the very high value of $q_{L}^{*}$ is due to the fact that the weight $\omega_{L}$ increases with income, with no weight assigned to voters with no income. We have also seen, when comparing $q_{R}^{*}$ to $q_{L}^{*}$, that he equilibrium tax rate increases further if one assigns a weight of zero to low-income people and not just to those with no income. This raises the following question: How does assigning a positive weight to voters with no incomes change the equilibrium tax rates? To study this question, we next assume that the weights $\phi(\theta)$ are increasing in income and linear (affine, to be precise). That is, we assume that parties maximize

$$
\int_{H}[\zeta+\gamma m(\theta)] v(q, I(\theta), Y) d F(\theta),
$$

where $\zeta$ and $\gamma \geqq 0$ are constants (with at least one being strictly positive). We then reduce the two degrees of freedom that we have in setting $\zeta$ and $\gamma$ by assuming that all weights schedules should pass through the point where the weights schedules used by Democratic and Republican militants cross. The utilitarian schedule and the linear schedule used by the Democratic militants constitute two extreme cases of this family. The former assigns the same positive weight $(\zeta>0$ and $\gamma=0)$ to everyone, resulting in $q^{F B}$; while the latter sets $\zeta=0$ and $\gamma>0$, resulting in $q_{L}^{*}$.

Table 1 reports the equilibrium tax rates for three intermediate cases corresponding to a small, a medium, and a large value of $\zeta$. Figure 1 shows these three intermediate schedules, together with the constant weights and the weights used by Democratic and Republican militants. ${ }^{23}$ A larger value of $\zeta$ (and thus lower value of $\gamma$ ) is associated more closely with an egalitarian situation where the parties give the same weight to all citizens, i.e. to a perfectly representative democracy. Accordingly, we see from Table 1 that larger values of $\zeta$ generate equilibria closer to the utilitarian/Pigouvian tax level. We nevertheless find that even with a large $\zeta$ the equilibrium tax is very high, exceeding $100 \%$ with $\alpha \leq 0.25$.

\footnotetext{
${ }^{23}$ The small value of $\zeta$ is one fourth the value that $\zeta$ takes with the utilitarian schedule.
} The medium corresponds to one half, and the large intercept to three fourth; see Figure 1. 
Figure 1 : Weight as a function of total individual income

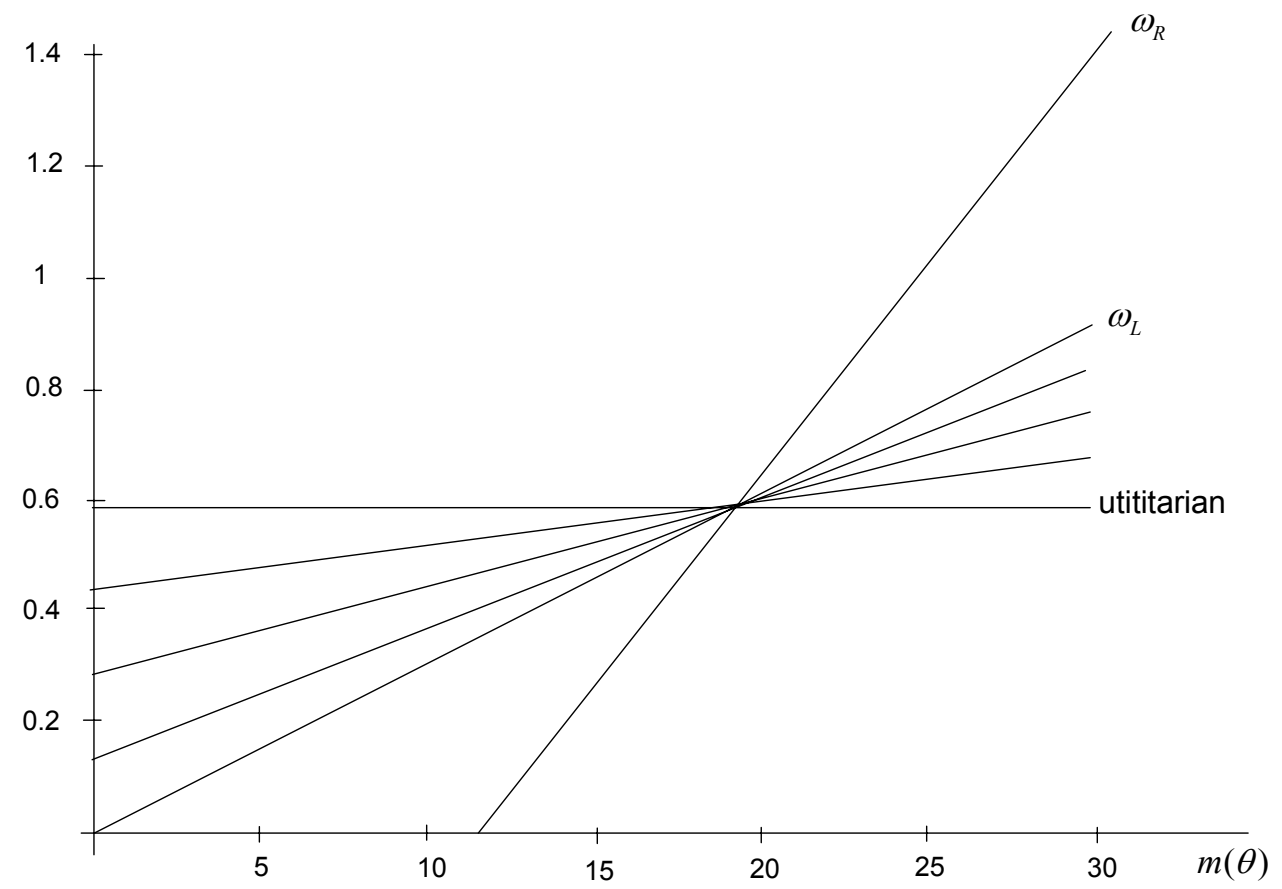

Figure 1: 
Finally, we find that the equilibrium tax rate under probabilistic voting decreases with $\alpha$ when weights are increasing in income. The reason for this comparative statics result is linked to the relative skewness of the labor versus capital income distributions, as explained in the previous section.

We conclude this section by pointing out a property that is shared by all political economy equilibrium concepts studied in Table 1 . When the equilibrium concept yields a subsidy, as in the majority-voting equilibrium, both $q^{M C}$ and $q^{M V}$ increase with $\alpha$. On the other hand, when the equilibrium concept yields a tax, as in the probabilistic voting equilibria and the PUNEs, the solutions decrease with $\alpha$. Consequently, increasing $\alpha$ moves the predicted equilibrium tax rates of all our political models closer to the Pigouvian level and to their actual observed values.

\section{Concluding remarks}

This paper has investigated if the existing energy taxes in the US can be explained through political economy models. It has examined the predictions of three competing models for the determination of energy taxes. The first is the traditional Downsian majority-voting equilibrium approach which calls for subsidizing energy goods. Intuitively, this follows from the facts that energy taxes are regressive and income distribution is skewed to the right. The other two models are the probabilistic-voting model, and Roemer's (2001) model of political competition with the "Party Unanimity Nash Equilibrium" (PUNE) as the equilibrium solution concept. In this latter setup, each party consists of two factions: one cares about the policies (militants), and the other about the probability of winning the election (opportunists). This approach incorporates the realistic feature of the two parties offering distinct policy platforms. A second important feature of our study is that our models have been calibrated on the basis of the US data. The voters are U.S. households as represented by the 2001 PSID survey, and the parameters of their utility function are calculated using U.S. studies.

We have shown that while the majority-voting approach to political competition leads to a massive subsidy on polluting goods, the probabilistic-voting equilibrium and the PUNE approaches lead to a huge tax - much higher than what one observes in the US economy. Our results suggest that, among the three political approaches studied, the probabilistic model, wherein parties assume that the proportion of unbiased voters is the same in all categories of income, comes closest to explaining the observed US energy taxes.

We cannot, nevertheless, claim either that our probabilistic voting model 
depicts reality, not by a long shot. There are three broad sets of reasons for this. First, our economic model is incomplete; second, the political approaches we have considered may not be the most appropriate ones; third, the calibration exercise may be inadequate and needs improvement. As for the economic model, we have made numerous simplifying assumptions and used only stylized parameter values that are consistent with this particular model. Additionally, our results rely on a postulated refund program which does not quite match actual practice. Nor does one know if any portion of current energy taxes are levied for environmental reasons. This suggests constructing a model that, in addition to externality correction, accounts for the revenue raising role of the tax system and incorporates the provision of public goods.

Second, our various models of the political decision making process may not represent how environmental policy is made in the U.S. A better description may be a political process that models the interaction between Congressional committees, the various lobbying groups, and the unelected bureaucrats at the Department of Energy. Observe also that the model we have developed in the paper, is concerned with the choice of a single environmental tax rate. Political models might perform better if environmental taxes were decided jointly with other policy instruments (such as the choice of $\alpha$ in our framework). A better understanding of how environmental policy is made is certainly needed.

Third, regarding calibrations, we lack a precise estimate of either the US energy tax rate, the portion that may have been levied for environmental reasons, or the Pigouvian tax rate (marginal social damages of pollution). Using other estimates, or looking at some other energy taxes, not just gasoline, actual and optimal tax rates might differ from each other. ${ }^{24}$ We have calibrated the model using a value for the price elasticity of demand that is appropriate for a static model with a one time change in the tax rate. One would expect that demand elasticities for energy to vary over short and long term horizons. With this in mind, it would be interesting to contrast our results with those that may follow from a dynamic model with sequential voting, calibrated using short term elasticities. Another problem is due to the specific weights we have used in calculating the PUNEs and the probabilistic equilibria (i.e. Bartels (2002) weights). The extremely high tax rates under PUNEs are essentially dictated by the preferences of the militants in the Democratic and the Republican parties, and especially by the fact that the militants in both parties put higher weights on richer individuals' preferences. More research is needed to enhance our understanding of how the parties evaluate their constituents' contribution

\footnotetext{
${ }^{24}$ It would be especially relevant to look at a pollutant that, unlike carbon, is not a global pollutant.
} 
to their own aspirations, ${ }^{25}$ and to their success in winning elections.

To conclude, a better understanding of how energy taxes are determined is needed. Political economy models, at least those that we have studied, and subject to the caveats we have mentioned, do not appear to tell the whole story.

\footnotetext{
${ }^{25}$ As observed by a referee, the results of Bartels (2002)'s regressions are not strong. In particular, the intercept - which plays a large role in our PUNE results - is not even close to being statistically significant. If this intercept were zero, Republicans and Democrats would have the same preferred tax policies. Additionally, the Bartels' estimates come from ideological responses of Senators to voter ideology, not from questions related directly to the environment.
} 


\section{Appendix}

\section{Proof of Lemma 1}

The first-order condition for the most-preferred level of $q$ is given by

$$
\frac{\partial V(q ; m, \delta)}{\partial q}=a^{\prime}(q)+m b^{\prime}(q)+\delta\left[b^{\prime}(q) R(q)+b(q) R^{\prime}(q)\right]-\varphi^{\prime}(\bar{y}(q)) \bar{y}^{\prime}(q)=0 \text {. }
$$

Observe that $\alpha$ enter this expression only through $\delta$ proving part (i). Differentiating (A1) with respect to $\delta$ and $q$ then yields equations (11)-(12) in the text, where $\partial^{2} V(q, \alpha, \theta) / \partial q^{2}<0$ by the concavity assumption (second-order condition). This proves part (ii).

With quasi-linear preferences, $d(q)=0$. Substituting in (11) yields:

$$
\frac{d \widetilde{q}}{d \delta}=\frac{b(q) R^{\prime}(q)}{-\partial^{2} V(q, \alpha, \theta) / \partial q^{2}}>0
$$

Consequently, $\widetilde{q}$ increases with $\delta$, which also implies that $q^{*}$ increases with $r$ and $w$ (for a given value of $\alpha$ ). To complete the proof it is then sufficient to note that when $b^{\prime}(q)=0$ and $\delta=1$ (A1) reduces to

$$
\left[\varphi^{\prime}-(q-1)\right] y^{\prime}(q)=0
$$

which yields $q^{*}=q^{F}$.

Calibrations of the parameters: Assuming that,

$$
\left\{\begin{array}{l}
a(q)=-a_{0} q+\frac{2 a_{1}+\beta a_{0}}{2} q^{2}-\frac{2 a_{1} \beta}{3} q^{3}, \\
b(q)=1-\beta q,
\end{array}\right.
$$

and given the indirect utility function (1) in the text, the demand function is given by

$$
\begin{aligned}
y(q, I)=-\frac{\partial v / \partial q}{\partial v / \partial I} & =\frac{-a^{\prime}(q)}{b(q)}-\frac{b^{\prime}(q)}{b(q)} I \\
& =\frac{a_{0}-\left(2 a_{1}+\beta a_{0}\right) q+2 a_{1} \beta q^{2}}{1-\beta q}+\frac{\beta}{1-\beta q} I \\
& =a_{0}-2 a_{1} q+\frac{\beta}{1-\beta q} I .
\end{aligned}
$$

It then follows from this equation that

$$
\begin{aligned}
\frac{\partial y(q, \bar{I})}{\partial q} \frac{q}{\bar{y}} & =\left[-2 a_{1}+\left(\frac{\beta}{1-\beta q}\right)^{2} \bar{I}\right] \frac{q}{\bar{y}} \\
\frac{\partial y(q, \bar{I})}{\partial \bar{I}} \frac{\bar{I}}{y(q, \bar{I})} & =\frac{\beta}{1-\beta q} \overline{\bar{y}} .
\end{aligned}
$$


Next, using equations (A2)-(A4), and the following three pieces of information,

(i) Consumer price of consumption goods $=1$

Consumer price of energy $=1$

$$
\begin{aligned}
& q=1 \\
& \bar{I}=59.9 \\
& \bar{y}=y(1, \bar{I})=3.324,
\end{aligned}
$$

where we have calculated $\bar{y}=3.324$ from

$$
\begin{aligned}
& \bar{y}=\text { average expenditure on energy }= \\
& (\text { ratio of average expenditure on energy to average income }) \\
& \times(\text { average income })= \\
& 0.0555 \times \$ 59,926= \\
& \$ 3,324
\end{aligned}
$$

(ii)

$$
\frac{\partial y(q, \bar{I})}{\partial q} \frac{q}{\bar{y}}=-0.3
$$

(iii)

$$
\frac{\partial y(q, \bar{I})}{\partial \bar{I}} \frac{\bar{I}}{y(q, \bar{I})}=0.40546
$$

we can calibrate the values of $a_{0}, a_{1}$, and $\beta$, by solving the following three equations:

$$
\begin{aligned}
a_{0}-2 a_{1}+\frac{\beta}{1-\beta} 59.9 & =3.324, \\
{\left[-2 a_{1}+\left(\frac{\beta}{1-\beta}\right)^{2} 59.9\right] \frac{1}{3.324} } & =-0.3, \\
\frac{\beta}{1-\beta} \frac{59.9}{3.324} & =0.40546 .
\end{aligned}
$$

This yields $\beta=0.022, a_{0}=3.003$, and $a_{1}=0.513$. 


\section{References}

Alesina, A. and H. Rosenthal, 1995, Partisan Politics, Divided Government, and the Economy. Cambridge University Press, Cambridge, MA.

American Petroleum Institute, March 2007, State gasoline tax reports, http://www.api.org/statistics/fueltaxes/upload/

March_2007_gasoline_and_diesel_summary_pages_2.pdf.

Bartels, L., 2002, Economic inequality and proportional representation, mimeo Princeton University.

Branch, E.R., 1993, Short run income elasticity of demand for residential electricity using consumer expenditure survey data, Energy Journal 14, 111-121.

Champernowne, D.G. and F.A. Cowell, 1998, Economic Inequality and Income Distribution, Cambridge University Press.

Cremer, H., P. De Donder and F. Gahvari, 2004a, Taxes, budgetary rule and majority voting, Public Choice 119, 335-358.

Cremer, H., P. De Donder and F. Gahvari, 2004b, Political sustainability and the design of environmental taxes, International Tax and Public Finance 11, 703-719.

Cremer, H., P. De Donder and F. Gahvari, 2007, Political competition within and between parties: an application to environmental policy, mimeo University of Illinois at Urbana-Champaign.

Downs, A., 1951, An Economic Theory of Democracy, New York: Harper Collins.

Filippini, M., 1999, Swiss Residential Demand for Electricity, Applied Economic Letters 6, 533.

Gately, D. and H.G. Huntington, 2001, The Asymmetric Effects of Changes in Price and Income on Energy and Oil Demand, Economic Research Report of the C.V. Starr Center for Applied Economics, New York. Environmentally Related Taxes database.

Hodge, J.T., 1999, A cointegration analysis of U.S. energy demand elasticities, mimeo Colorado School of Mines.

Hofferbert, R. and I. Budge, 1992, The party mandate and the Westminster model: election programmes and government spending in Britain, British Journal of Political Sciences 22, 151-182. 
Hofferbert, R. and H. Klingemann, 1990, The policy impact of party programs and government declarations in the Federal Republic of Germany. European Journal of Political Research 18, 277-304.

Lindbeck, A. and J. Weibull, 1987, Balanced budget redistribution as the outcome of political competition, Public Choice 52, 273297.

Mathis, E.J. and C.E. Zech, 1989, The median voter model fails an empirical test: The procedure, useful in the absence of a better one, is not valid for multidimensional issues, American Journal of Economics and Sociology 48, 79-87.

National Institute of Economics and Industry Research, 2002, The price elasticity of demand for electricity in NEM regions, Report for the National Electricity Market Management Company, Victoria, Australia.

Ninomiya, Y., 2002, Energy demand in Japan - an analysis of the past trend, Presentation at the International Workshop on Climate Policy Dialogue in Thailand, Bangkok.

Persson, T. and G. Tabellini, 2000, Political Economics. Explaining Economic Policy, The MIT Press, Cambridge: MA.

Poole, K. and H. Rosenthal, 1984a, The polarization of American politics, Journal of Politics 46, 1061-1079.

Poole, K. and H. Rosenthal, 1984b, US presidential elections 19681980: A spatial analysis, American Journal of Political Science 35, 228-278.

Poterba, J.M., 1991, Tax policy to combat global warming: on designing a carbon tax, in R. Dornbusch and J.M. Poterba, eds., Global Warming: Economic Policy Responses, The MIT Press, Cambridge, Massachusetts, 71-98.

Roemer, J., 2001, Political Competition: Theory and Applications, Harvard University Press.

Romer, T. and H. Rosenthal, 1979, The elusive median voter, Journal of Public Economics 12, 143-170.

Turnbull, G.K. and G. Geon, 2006, Local government internal structure, external constraints and the median voter, Public Choice 129, 487-506. 
Turnbull, G.K. and P.M. Mitias, 1999, The median voter across levels of government, Public Choice 99, 119-138.

U.S. Department of Transportation, 2007, Monthly motor fuel reported by states September 2006, Federal Highway Administration, Publication No. FHWA-PL-07-006. 